\title{
Insight into the genetic variability analysis and cultivar identification of tall fescue by using SSR markers
}

\author{
Kaixin $\mathrm{Fu}^{1 \dagger}$, Zhihui Guo ${ }^{1 \dagger}$, Xinquan Zhang ${ }^{1}$, Yan Fan², Wendan Wu', Daxu Li³, Yan Peng ${ }^{1}$, Linkai Huang ${ }^{1}$, \\ Ming Sun', Shiqie Bai ${ }^{3^{*}}$ and Xiao Ma ${ }^{1 *}$
}

\begin{abstract}
Background: Genetic diversity of 19 forage-type and 2 turf-type cultivars of tall fescue (Festuca arundinacea Schreb.) was revealed using SSR markers in an attempt to explore the genetic relationships among them, and examine potential use of SSR markers to identify cultivars by bulked samples.

Results: A total of 227 clear band was scored with 14 SSR primers and out of which 201 (88.6 \%) were found polymorphic. The percentage of polymorphic bands (PPB) per primer pair varied from 62.5 to $100 \%$ with an average of $86.9 \%$. The polymorphism information content (PIC) value ranged from 0.116 to 0.347 with an average of 0.257 and the highest PIC value (0.347) was noticed for primer NFA040 followed by NFA113 (0.346) whereas the highest discriminating power (D) of 1 was shown in NFA037 and LMgSSR02-01C. A Neighbor-joining dendrogram and the principal component analysis identified six major clusters and grouped the cultivars in agreement with their breeding histories. STRUCTURE analysis divided these cultivars into 3 sub-clades which correspond to distance based groupings.

Conclusion: These findings indicates that SSR markers by bulking strategy are a useful tool to measure genetic diversity among tall fescue cultivars and could be used to supplement morphological data for plant variety protection.
\end{abstract}

Keywords: Tall fescue, SSR markers, Genetic diversity, Cultivar identification, Principal component analysis, Neighbor joining, Population structure

\section{Background}

Festuca arundinacea Schreb., commonly known as tall fescue is the predominant cool-season perennial grass that is widely grown throughout the temperate regions of the world [1]. It forms the forage basis for beef cow and calf production and also is widely used as turf in lawns, parks, football fields, highway medians, and roadsides [2]. It is a cross-pollinated allohexaploid $(2 \mathrm{n}=6 \mathrm{x}=$ 42) with the genomic constitution $P^{P} G_{1} G_{1} G_{2} G_{2}$ and a high degree of self-incompatibility $[3,4]$. These features make breeding efforts generally focus on the

\footnotetext{
*Correspondence: baiturf@qq.com; maroar@126.com

${ }^{\dagger}$ Equal contributors

${ }^{3}$ Sichuan Academy of Grassland Science, Chengdu 611731, China

${ }^{1}$ Animal Science and Technology College, Sichuan Agricultural University,

Chengdu 611130, China

Full list of author information is available at the end of the article
}

development of superior synthetic cultivars or improved heterogeneous populations, both of which consist of genetically unique individuals that share many characters $[5,6]$. Simultaneously, the relative drought tolerance of tall fescue and climatic changes are leading to increased cultivation in the transitional climates between temperate and subtropical zones [7]. The demand for forage type cultivars of tall fescue has resulted in the development and release of hundreds of cultivars since 1940s [7].

The accurate description of genetic diversity in natural and artificial populations and identification of elite tall fescue cultivars rely on molecular techniques since morphological traits are easily vulnerable to environmental conditions and often showed the limited efficiency of detection of inter-varietal and intra-varietal polymorphisms 
on account of environmental plasticity [8]. Molecular marker analysis offers an efficient approach for assessing genetic diversity and germplasm characterization in cross-pollinated grass species $[9,10]$. In view of cheapness and effectiveness, bulking strategy has been successfully employed to investigate genetic variation between cultivars of allogamous species [11]. Additionally, a value of 20 genotypes per population seems appropriate for most foragegrass species [12]. RFLP and AFLP have been used to distinguish several cultivars of tall fescue by pooled DNA samples $[8,13]$, but these methods require more technically demanding skills than conventional PCR markers [14]. Simple sequence repeats (SSR) have become one of the most widely used molecular marker systems in plant genetics due to the codominant inheritance, relative abundance, multi-allelic nature, extensive genome coverage, high reproducibility, and simple detection [15]. A large number of SSR markers have been developed for the Lolium/Festuca complex species, such as tall fescue $[15,16]$ and $L$. multiflorum [17]. Moreover, it has been reported that SSR markers has showed a high transferability across closely related species [18].

To date, the old cultivar Kentucky-31 and its derived cultivars bred in North America have been widely introduced to other parts of the world as a forage base for beef, wool and dairy production [19]. However, there is little information about the genetic relationships between these popular cultivars. The objective of the present work, therefore, was (i) to reveal patterns of molecular polymorphism and (ii) to survey the extent of genetic variability and relationships among some elite cultivars of tall fescue from North America and Europe by using SSR markers and bulked samples. Here we wanted to confirm known genetic relationships among these cultivars based on recorded pedigrees and to evaluate the usefulness of SSR markers for germplasm identification.

\section{Methods}

Plant material and DNA extraction

Nineteen forage- and two turf-type cultivars of tall fescue (F. arundinacea Schreb.) were included in this experiment, all of whose seeds were provided by National Plant Germplasm System of USDA. Pedigree or breeding history information of 21 cultivars could be traced, listed in the Table 1. Two of all cultivars, viz., Willamette and Carefree belong to turf-type, while the rest are foragetype. Seed was germinated at $26{ }^{\circ} \mathrm{C}$ on blotter paper in a lighted growth chamber. Bulked samples were composed

Table 1 Description of the plant material analyzed

\begin{tabular}{|c|c|c|c|}
\hline Cultivar & Country & Origin/Pedigree & Registration date \\
\hline Kenhy & U.S. & 11 42-chromosome Lolium multiflorum $\times F$. arundinacea clones & 1977 \\
\hline Cajun & U.S. & cultivar AuTriumph & 1989 \\
\hline Maximize & U.S. & ecotypes from southeast France & 1993 \\
\hline Kentucky 31 & U.S. & ecotype from temperate pasture in Kentucky & 1972 \\
\hline Kenwell & U.S. & three inbred lines & 1968 \\
\hline Alta & U.S. & a 4-year-old plant selection in Oregon. & 1945 \\
\hline Fawn & U.S. & temperate 8-clone synthetic & 1974 \\
\hline Martin & U.S. & 2 clones from broad based population. & 1987 \\
\hline Missouri-96 & U.S. & 13 clones from France germplasm & 1979 \\
\hline Forager & U.S. & Kenwell, Fawn, Kentucky 31, etc. & 1980 \\
\hline Barcel & Netherland & 13 temperate clones from Netherlands & 1981 \\
\hline Johnstone & U.S. & $\begin{array}{l}\text { blend of two strains of Kenhy derivatives and } 42 \text {-chromosome } \\
\text { Lolium sp. } \times \text { F. arundinacea hybrid clones }\end{array}$ & 1983 \\
\hline Au triumph & U.S. & an open pollinated population AF-5 comprised of 12 genotypess & 1983 \\
\hline Willamette & U.S. & an open pollinated progeny of 5 elite parental clones & 1985 \\
\hline Safe & U.S. & Kenhy and two germplasm with diseases and drought resistance & 1985 \\
\hline Barvetia & Netherland & temperate 13 -clone synthetic & unavailable \\
\hline Mozark & U.S. & Kenmont, Kentucky-31, and introductions from Algeria and France & 1987 \\
\hline Penngrazer & U.S. & Kentucky 31 & 1988 \\
\hline Cattleclub & U.S. & Kentucky 31 & 1988 \\
\hline Carefree & U.S. & Houndog, Rutgers, and GPTF accessions. & 1989 \\
\hline Nanryo & Japan & Fawn, Kentucky 31, Rozelle, Electa, Krasnadorskaja and Yamanami & 2006 \\
\hline
\end{tabular}


by DNA extraction from pooled tissue samples consisting of single leaves from each of the 20 randomly selected plants, for each cultivar. Total genomic DNA was isolated from bulked leaves according to the protocol of using a modified CTAB method [20]. The quality and concentration of the extracted DNA were determined by Nano-Drop ND 2000 spectrophotometer (NanoDrop Technologies, Inc.) and $1 \%(\mathrm{w} / \mathrm{v})$ agarose gels electrophoresis. The isolated genomic DNA was diluted to 10 $\mathrm{ng} / \mu \mathrm{L}$ and stored at $-20{ }^{\circ} \mathrm{C}$ for use.

\section{SSR maker primers and SSR-PCR amplification}

A total of 15 SSR markers (Table 2) were used to characterize 21 cultivars tall fescue, of which primer LMgSSR02-01C is genic-SSR markers from annual ryegrass [17], the remaining 14 were EST-SSR markers from tall fescue [15]. Each $15 \mu \mathrm{L}$ amplification reaction consisted of $3.0 \mu \mathrm{L}$ of template DNA $(10 \mathrm{ng} / \mu \mathrm{L}), 0.6 \mu \mathrm{L}$ primer $(5 \mathrm{pM}), 0.3 \mu \mathrm{L}$ of Taq polymerase $(2.5 \mathrm{U} / \mu \mathrm{L}), 3 \mu \mathrm{L}$ of sterile distilled water and $7.5 \mu \mathrm{L}$ of $2 \times$ Taq PCR Master Mix (Tiangen Biotech, Beijing, China). Touchdown PCR amplification was carried out under the following conditions: $5 \mathrm{~min}$ at $95{ }^{\circ} \mathrm{C} ; 16$ cycles of $95{ }^{\circ} \mathrm{C}$ for $50 \mathrm{~s}$, $68{ }^{\circ} \mathrm{C}$ with $0.5{ }^{\circ} \mathrm{C}$ decrease per cycle for $50 \mathrm{~s}$ until the annealing temperature reached $60{ }^{\circ} \mathrm{C}$, and $72{ }^{\circ} \mathrm{C}$ for 1 min; 19 cycles of $95{ }^{\circ} \mathrm{C}$ for $50 \mathrm{~s}, 60{ }^{\circ} \mathrm{C}$ for $50 \mathrm{~s}, 72{ }^{\circ} \mathrm{C}$ for $1 \mathrm{~min}$; followed by a final extension at $72{ }^{\circ} \mathrm{C}$ for $10 \mathrm{~min}$, and in the end $4{ }^{\circ} \mathrm{C}$ as a holding temperature. The PCR amplification products were electrophoresed in $8 \%$ non- denaturing polyacrylamide gel at $150 \mathrm{~V}$ for $30 \mathrm{~min}$, followed by $2 \mathrm{~h}$ at $350 \mathrm{~V}$. Then the gels were visualized by silver staining $f$ and photographed by a gel scanner.

\section{Data analysis}

In spite of co-dominant nature of SSR, there is great difficulty in allele calling by amplified pattern because of the allohexaploid nature of tall fescue and the bulking strategy used in present study. Therefore, unequivocally scorable bands were scored manually as either present (1) and absent $(0)$ to create the binary raw data matrix for further analysis. The total number of bands (TB) and polymorphic bands $(\mathrm{PB})$, polymorphic rate $(\mathrm{P})$, Shannon information index (I) [21], and polymorphism information content (PIC) [22] were calculated as MS Excel 2010, using the formula: $\mathrm{PIC}=1-\sum \mathrm{P}_{\mathrm{ij}}^{2}$, where $\mathrm{P}_{\mathrm{ij}}$ is the frequency of the $j$ th allele (marker) for the $i$ th SSR locus. The distinguished varieties (DV), which were calculated by the number of unique sequences required to identify a particular cultivar from the clustering dendrogram of all 21 cultivars. To compare the efficiency of the markers in varietal identification, the discrimination power (D) [23] was estimated for each primer. This parameter was calculated in accordance with the formula as follows: $D=1-\sum_{i=1}{ }^{I} p i \frac{(N p i-1)}{\overline{N-1}}$, where $\mathrm{D}$ is the probability that two randomly selected samples have different and distinct banding patterns, $p_{i}$ is the frequency of the $i$ th pattern revealed by each primer, $\mathrm{N}$ is the number of samples analyzed and $I$ is the total

Table 2 Characteristics of 15 SSR markers selected for use in the study

\begin{tabular}{|c|c|c|c|c|c|c|c|c|c|c|}
\hline Primes & motif & Size range (bp) & NTB & NPB & PPB (\%) & PIC & I & CSM & DV & $D$ \\
\hline LMgSSR02-01C & $(\mathrm{aac})_{26}$ & $86-193$ & 24 & 23 & 95.8 & 0.252 & 0.403 & 3 & 21 & 1.000 \\
\hline NFA018 & $(\mathrm{cgg})_{6}$ & 136-198 & 10 & 9 & 90 & 0.267 & 0.411 & 2 & 12 & 0.952 \\
\hline NFA021 & $(\mathrm{cct})_{7}$ & $191-358$ & 14 & 12 & 85.7 & 0.259 & 0.402 & 1 & 12 & 0.971 \\
\hline NFA022 & $(\operatorname{agg})_{6}$ & 180-391 & 15 & 13 & 86.7 & 0.269 & 0.410 & 3 & 13 & 0.967 \\
\hline NFA035 & $(g g c)_{6}$ & $177-371$ & 16 & 10 & 62.5 & 0.193 & 0.293 & 3 & 8 & 0.914 \\
\hline NFA037 & $(\mathrm{acc})_{6}$ & $177-384$ & 25 & 24 & 96 & 0.279 & 0.434 & 4 & 21 & 1.000 \\
\hline NFA040 & $(\mathrm{cgg})_{6}$ & $233-404$ & 12 & 12 & 100 & 0.347 & 0.518 & 1 & 15 & 0.986 \\
\hline NFA050 & $(\mathrm{cag})_{7}$ & $187-361$ & 8 & 5 & 62.5 & 0.116 & 0.205 & 1 & 1 & 0.267 \\
\hline NFA060 & $(\operatorname{tag})_{8}$ & $205-350$ & 13 & 12 & 92.3 & 0.237 & 0.383 & 2 & 13 & 0.967 \\
\hline NFA065 & $(\operatorname{agc})_{6}$ & $200-344$ & 18 & 18 & 100 & 0.298 & 0.461 & 3 & 19 & 0.995 \\
\hline NFA066 & $(\mathrm{cct})_{6}$ & $165-267$ & 11 & 9 & 81.8 & 0.250 & 0.380 & 2 & 11 & 0.962 \\
\hline NFA113 & $(\mathrm{cgg})_{6}$ & $161-357$ & 19 & 18 & 94.7 & 0.346 & 0.514 & 1 & 19 & 0.995 \\
\hline NFA133 & $(\mathrm{cgg})_{7}$ & $162-268$ & 16 & 15 & 93.8 & 0.274 & 0.424 & 3 & 15 & 0.967 \\
\hline NFA150 & $(\mathrm{ctg})_{7}$ & $173-297$ & 13 & 10 & 76.9 & 0.306 & 0.443 & 1 & 12 & 0.971 \\
\hline NFA153 & $(\mathrm{gca})_{7}$ & 187-294 & 13 & 11 & 84.6 & 0.170 & 0.286 & 5 & 9 & 0.900 \\
\hline Total & - & & 227 & 201 & 88.6 & - & - & 35 & 21 & 1 \\
\hline Mean & - & & 15.1 & 13.4 & 86.9 & 0.257 & 0.398 & 2.3 & 13.4 & 0.920 \\
\hline
\end{tabular}

NTB number of total bands, NPB number of polymorphic bands, PPB percentage of polymorphic bands, PIC polymorphic information content, I Shannon's information index, CSM Cultivar-specific markers (presence and absence), DV Distinguished varieties, $D$ discriminating power 
number of patterns generated by each primer [23]. The presence/absence data matrix was further used to calculate genetic similarity (GS) between pairs of cultivars according to Dice's similarity coefficient using NTSYSpc v2.2 [24]. Then a genetic distance (GD) matrix developed as $\mathrm{GD}=1-\mathrm{GS}$ was used to construct dendrograms based on the neighbour-joining (NJ) clustering method with a bootstrapping value of 10,000 replications by the FreeTree software [25]. To verify the adjustment between genetic distance matrices and respective dendrogram-derived matrices (cophenetic matrix), the cophenetic correlation coefficient ( $\mathrm{r}$ ) was estimated by NTSYSpc v2.2. As well as the principal coordinate analysis ( $\mathrm{PCoA}$ ) was obtained by the similarity matrix, which was computed from the same program. Further, Bayesian model-based cluster analysis was performed to infer genetic structure and to define the number of clusters in the data set using the software STRUCTURE version 2.3.4 [26]. The membership of each cultivars was tested for the range of genetic clusters from $\mathrm{K}=1$ to 10 with admixture model and without prior information on their origin. Twenty independent runs were assessed for each fixed $\mathrm{K}$ and each run consisted of 20,000 burn-in period and 50,000 MCMC iterations. The most likely value of $\mathrm{K}$ was determined by examination of the $\Delta \mathrm{K}$ statistic and $\mathrm{L}(\mathrm{K})$ [27] using Structure Harvester [28]. A consensus STRUCTURE plot was obtained from the admixture repeats using the greedy algorithm in CLUMPP version 1.1 [29], and final plots were produced in STRUCTURE PLOT [30]. Within a subgroup, cultivars with inferred ancestry based on probability values $\geq 60 \%$ were assigned to a different group, and those with $<60 \%$ were treated as "admixture", i.e., these cultivars seem to have a mixed ancestry from parents belonging to different origins or gene pools.

\section{Results and discussion}

\section{Statistical analysis of SSR markers}

Due to the outbreeding nature of tall fescue, we used bulked samples that represent the mixture of genotypes with a cultivar. In the present work, genetic variability among the 21 tall fescue cultivars was analyzed using a set of SSR primer pairs (PPs), most of which originated from ESTs sequence of tall fescue [15]. Out of 100 original primer pairs (PPs), 15 selected PPs could generate reproducible and polymorphic patterns among the cultivars, and hence these 15 PPs were retained for further statistical analyses. Totally 227 bands were produced, of which 201 (88.6\%) were polymorphic with an average of 13.4 polymorphic bands per primer (Table 2 ). The number of scorable bands produced per PPs ranged from 8 (NFA050) to 25 (NFA037) with an average of 15.1, and amplicon size varied from 80 to $400 \mathrm{bp}$. The percentage of polymorphism varied between 62.5 (NFA035 and
NFA50) to 100 (NFA40 and NFA65) with an average value of $86.9 \%$.

The polymorphism information content (PIC) was in the range from 0.116 to 0.347 with an average value of 0.258 and PIC value was found to be highest with the primer NFA40 (0.347), followed by NFA113 (0.346) and NFA150 (0.306). Nine SSR primers showed more PIC than the average value (0.257). The Shannon index ranged from 0.205 to 0.518 and NFA40 showed highest diversity (0.518), followed by NFA113 (0.514); and average Shannon index was 0.398. Furthermore, the number of the evaluated cultivars distinguished by any SSR marker ranged from 1 to 21 , with an average of 13.4 per PPs. The discriminating power (D), a measure of the efficiency of a primer or a locus is an effective method to know the ability of a primer in distinguishing the crop genotypes [31]. In this study, D value ranged between 0.267 (NFA50) to 1 (NFA37 and LMgSSR02-01C) with an average value of 0.921 (Table 2). Here, 14 out of 15 SSR markers showed high discriminatory power $(>0.90)$, indicating that these 15 PPs used in this study were highly effective in tall fescue cultivar characterization. Primer NFA37 and LMgSSR02-01C, which showed the highest $\mathrm{D}$ value being one, was found to be the best SSR markers for detecting polymorphism in tall fescue. Although only 35 cultivar-specific markers were observed for 15 primers, all of 21 cultivars had their own unique SSR banding patterns individually, which could be used to distinguish cultivars by characteristic sets of bands.

\section{Dice's distance coefficient and hierarchical clustering}

Two hundred and twenty-seven fragments from 15 SSR loci were used to estimate pairwise Dice's distances among 21 tall fescue cultivars. The Dice's coefficient was moderately high, varying from 0.163 (Forager vs. Fawn) to 0.475 (AuTriumph vs. Barvetia), with an average of 0.320 (Table 3). These low values were similar to those obtained from studies about analyzing tall fescue cultivars and/or populations by RFLP [8] and AFLP [13], which were less than 0.50 among cultivars. The less genetic distance indicated a relatively low genetic diversity or a closer relationship among studied cultivars although some visible differences obviously exist between them. This is not surprising considering the breeding histories of these cultivars (Table 1). Some popular cultivars such as Kentucky 31 , often served as common parental germplasm to intercross with other limited germplasm in breeding program of many tall fescue cultivars [8]. Therefore, the similar pedigree or germplasm sources could account for the high genetic similarity and close relationship among cultivars evaluated. Likewise, seven perennial ryegrass cultivars representing a broad germplasm sample also showed high levels of genetic similarity using SSR markers [32]. Besides that, this low level of genetic diversity could be due in 
Table 3 Dice's distance matrix of 21 cultivars of tall fescue based on SSR profile

\begin{tabular}{|c|c|c|c|c|c|c|c|c|c|c|c|c|c|c|c|c|c|c|c|c|c|}
\hline & 1 & 2 & 3 & 4 & 5 & 6 & 7 & 8 & 9 & 10 & 11 & 12 & 13 & 14 & 15 & 16 & 17 & 18 & 19 & 20 & 21 \\
\hline Kenhy & 0 & & & & & & & & & & & & & & & & & & & & \\
\hline Cajun & 0.336 & 0 & & & & & & & & & & & & & & & & & & & \\
\hline Maximize & 0.313 & 0.295 & 0 & & & & & & & & & & & & & & & & & & \\
\hline Kentucky31 & 0.291 & 0.302 & 0.352 & 0 & & & & & & & & & & & & & & & & & \\
\hline Kenwell & 0.289 & 0.292 & 0.304 & 0.237 & 0 & & & & & & & & & & & & & & & & \\
\hline Alta & 0.294 & 0.245 & 0.243 & 0.306 & 0.268 & 0 & & & & & & & & & & & & & & & \\
\hline Fawn & 0.345 & 0.291 & 0.326 & 0.354 & 0.311 & 0.253 & 0 & & & & & & & & & & & & & & \\
\hline Martin & 0.415 & 0.418 & 0.322 & 0.384 & 0.364 & 0.322 & 0.307 & 0 & & & & & & & & & & & & & \\
\hline Missouri96 & 0.313 & 0.295 & 0.327 & 0.192 & 0.294 & 0.289 & 0.348 & 0.379 & 0 & & & & & & & & & & & & \\
\hline Forager & 0.366 & 0.293 & 0.316 & 0.343 & 0.313 & 0.257 & 0.163 & 0.285 & 0.306 & 0 & & & & & & & & & & & \\
\hline Barcel & 0.372 & 0.382 & 0.330 & 0.347 & 0.359 & 0.298 & 0.317 & 0.364 & 0.286 & 0.329 & 0 & & & & & & & & & & \\
\hline Johnstone & 0.219 & 0.370 & 0.340 & 0.288 & 0.256 & 0.272 & 0.341 & 0.361 & 0.310 & 0.340 & 0.322 & 0 & & & & & & & & & \\
\hline AuTriumph & 0.429 & 0.254 & 0.292 & 0.355 & 0.356 & 0.293 & 0.297 & 0.348 & 0.379 & 0.218 & 0.301 & 0.403 & 0 & & & & & & & & \\
\hline Willamette & 0.280 & 0.312 & 0.296 & 0.275 & 0.303 & 0.268 & 0.326 & 0.393 & 0.265 & 0.326 & 0.273 & 0.288 & 0.370 & 0 & & & & & & & \\
\hline Safe & 0.262 & 0.330 & 0.385 & 0.194 & 0.217 & 0.327 & 0.348 & 0.367 & 0.268 & 0.337 & 0.373 & 0.230 & 0.388 & 0.317 & 0 & & & & & & \\
\hline Barvetia & 0.345 & 0.431 & 0.449 & 0.387 & 0.367 & 0.380 & 0.377 & 0.361 & 0.440 & 0.398 & 0.406 & 0.365 & 0.475 & 0.408 & 0.360 & 0 & & & & & \\
\hline Mozark & 0.337 & 0.248 & 0.340 & 0.265 & 0.271 & 0.294 & 0.319 & 0.326 & 0.321 & 0.271 & 0.354 & 0.333 & 0.306 & 0.359 & 0.312 & 0.405 & 0 & & & & \\
\hline Penngrazer & 0.320 & 0.257 & 0.324 & 0.265 & 0.272 & 0.305 & 0.290 & 0.341 & 0.294 & 0.282 & 0.380 & 0.327 & 0.317 & 0.333 & 0.285 & 0.390 & 0.243 & 0 & & & \\
\hline Cattleclub & 0.337 & 0.350 & 0.330 & 0.188 & 0.245 & 0.260 & 0.360 & 0.358 & 0.248 & 0.330 & 0.303 & 0.277 & 0.360 & 0.292 & 0.240 & 0.445 & 0.281 & 0.273 & 0 & & \\
\hline Carefree & 0.356 & 0.316 & 0.339 & 0.265 & 0.327 & 0.313 & 0.320 & 0.422 & 0.274 & 0.340 & 0.395 & 0.371 & 0.370 & 0.321 & 0.376 & 0.447 & 0.307 & 0.300 & 0.333 & 0 & \\
\hline Nanryo & 0.345 & 0.330 & 0.294 & 0.344 & 0.344 & 0.295 & 0.190 & 0.256 & 0.326 & 0.200 & 0.317 & 0.352 & 0.277 & 0.326 & 0.358 & 0.389 & 0.289 & 0.301 & 0.330 & 0.289 & 0 \\
\hline
\end{tabular}


part, to the tall fescue's allogamy and self-incompatibility [3], as well as to its hexaploid composition [33]. Typically, the cross-pollinated species maintain relatively high intrapopulation variability as compared to its inter-population variability [12, 34]. The Analysis of molecular variance (AMOVA) indicated that most (92.3\%) of the molecular variation in wild Iranian tall fescue populations exists among individuals within populations, with lesser amounts among populations (7.7\%) [35]. As a result, the enormous intra-cultivar genetic variability led to the high genetic similarity among tall fescue cultivars.

A dendrogram was generated from the NJ cluster analysis of SSR data (Fig. 1). This dendrogram divided the 21 culitvars into six major clades in general agreement with their breeding origins with a few exceptions. A high correlation $(r=0.79, P<0.01)$ between the cophenetic matrix and the original matrix revealed a high goodness of fit for the cultivars clustering. Clade 1 consisted of three cultivars, Kenhy, Johnstone and Kenwell. Here, both Kenhy and Johnstone origined from derivatives of 11 42-chromosome Lolium $\times$ Festuca hybrid clones at Kentucky Agricultural Experiment Station (KAES) of USA [36-38]. Kenwell was also developed from three inbred lines at KAES and may provide share some common pollen sources with Kenhy and Johnstone [39], therefore it is not surprising that it was also included in Clade 1. Clade 2 was composed of Kentucky 31, Safe, Cattleclub, Missouri 96 and Carefree, whose clustering placement could be chiefly attributed to their pedigree origin. Kentucky 31 originated from a population that had undergone approximately 43 years of natural selection on a farm in Kentucky State of USA [37, 40]. And Cattleclub originated from several old Kentucky 31 seed fields by phenotypic selection [41]. However, Missouri96 was derived from plant introductions from France [42]. It was used as a pollen source in the development of Houndog, one of the first improved turf-type cultivar [37]. Moreover, six parental clones from Houndog was used to ploycross with other germplasm in the development of Carefree, a turf-type synthetic [41], which is the most dissimilar from the others found in Clade 2. Yet it is hard to explain the low distance of 0.194 between Safe and Kentucky 31, since Safe was derived from Kenhy existing in Clade 1 [41]. Clade 3 was randomly made up of Barcel and Willamette supported by a bootstrap value of $47 \%$, indicating that these two cultivars are distinctly different from the other cultivars in the study. Barcel derived from old pastures in the Netherlands [41], but there is little information available concerning the parentage of Willamette other than it may have some

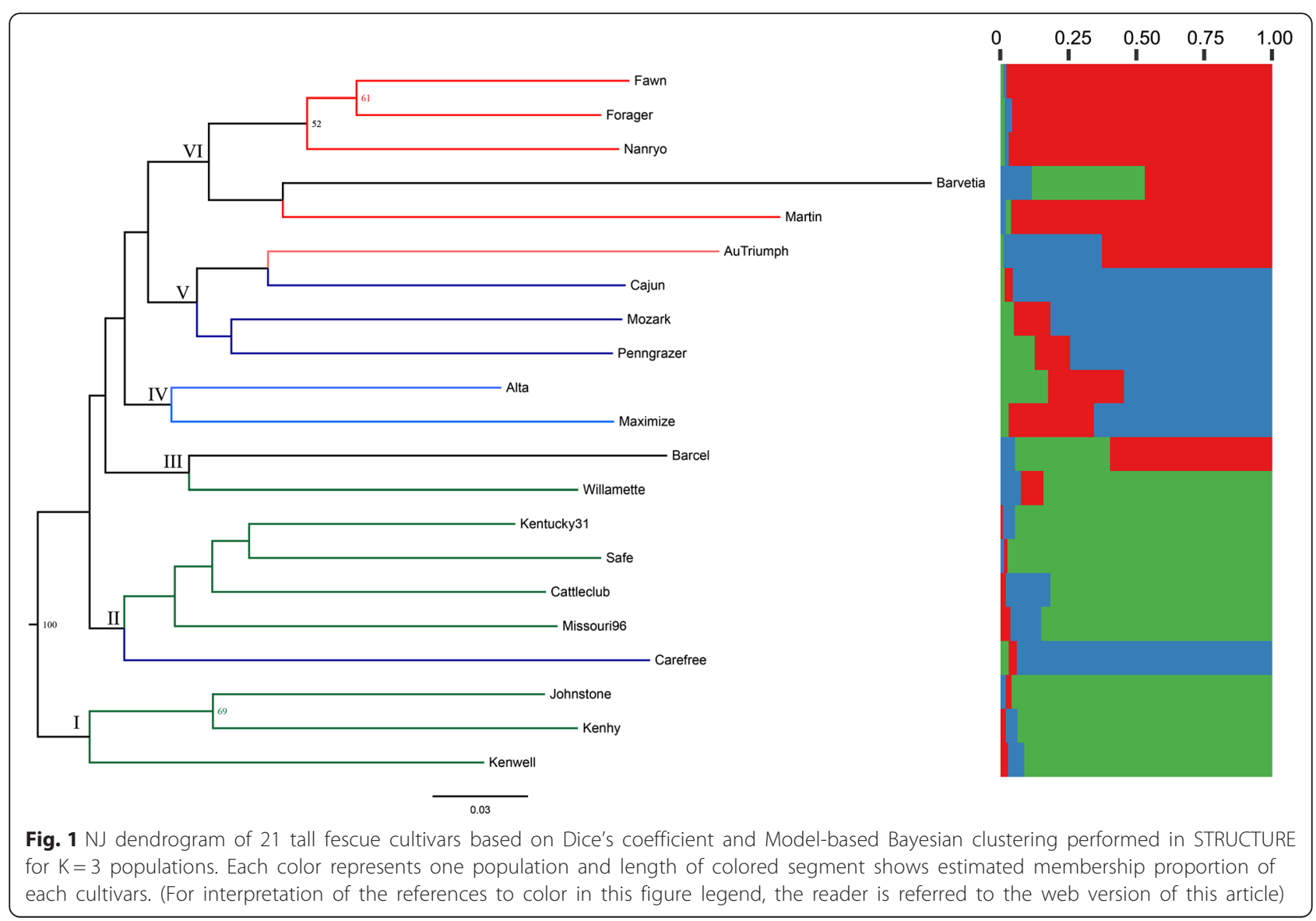


common germplasm with cultivar Houndog [37]. Clade 4 contained two cultivars Alta and Maximize with a high pairwise similarity of 0.76 , while it is hard to give a clear elucidation by their pedigree history. Alta was developed from a plant selection in Oregon [43], and Maximize was resulted from French ecotypes [44]. Clade 5 included four cultivars, viz., AuTriumph, Cajun, Mozark and Penngrazer. By and large, this clade came together as predicted by the breeding histories for these cultivars. AuTriumph was developed from 12 introduction genotypes and Cajun derived from AuTriumph $[45,46]$, while Penngrazer could trace to Kentucky 31, one of the four parent clones of Mozark was also Kentucky 31 [47]. However, Penngrazer and Mozark failed to group tighter with the Kentucky 31 in the Clade 2. The reason for that probably is that the nature of outcrossing and multiple mass selections resulted in an unequal contribution of parent plants in the final genetic makeup of a cultivar [48]. Clade 6 including five cultivars could be divided into sub-clades with three and one cultivar respectively. Here Forager and Nanryo sharing one of the common parent germplasm Fawn resulted to a firm genetic relationship with the high bootstrap values $[49,50]$. Additionally, Barvetia and Martin formed a sub-clade with a middle bootstrap value of $42 \%$, but this could not correspond to their pedigree information, since Barvetia was developed in Netherland and Martin was developed in Missouri university of USA $[8,47,51]$. Yet it was worth noting that most of NJ clusters showed lower bootstrap values below the $50 \%$, which suggested that more primers may be needed to identify genetic relationship between cultivars surveyed. In particular, the detailed pedigree information of some commercial or patented cultivars is desperately needed to explain the genetic relationship among different cultivars. In short, these results illustrated that SSR markers were effective in surveying the affinities among tall fescue cultivars studied.

The principal coordinate analysis ( $\mathrm{PCoA})$ was done to see the displacement of the cultivars and to further confirm the clustering pattern obtained from the dendrogram (Fig. 2). The first three eigenvectors accounted for $32.3 \%$ of total variation among all the cultivars. The first and second axes represented 13.7 and $10.1 \%$ of the variation respectively. The affinities produced by $\mathrm{PCoA}$ are generally in agreement with the NJ cluster and Dice's dissimilarity coefficients analyses. Some cultivars shared common parental resources were closely dispersed in the PCoA plot, as Nanryo, Forager and Fawn showed closely related each other on $\mathrm{NJ}$ dendrogram.

\section{Population structure}

The pattern of population structure was further analyzed with a Model based Bayesian approach implemented in

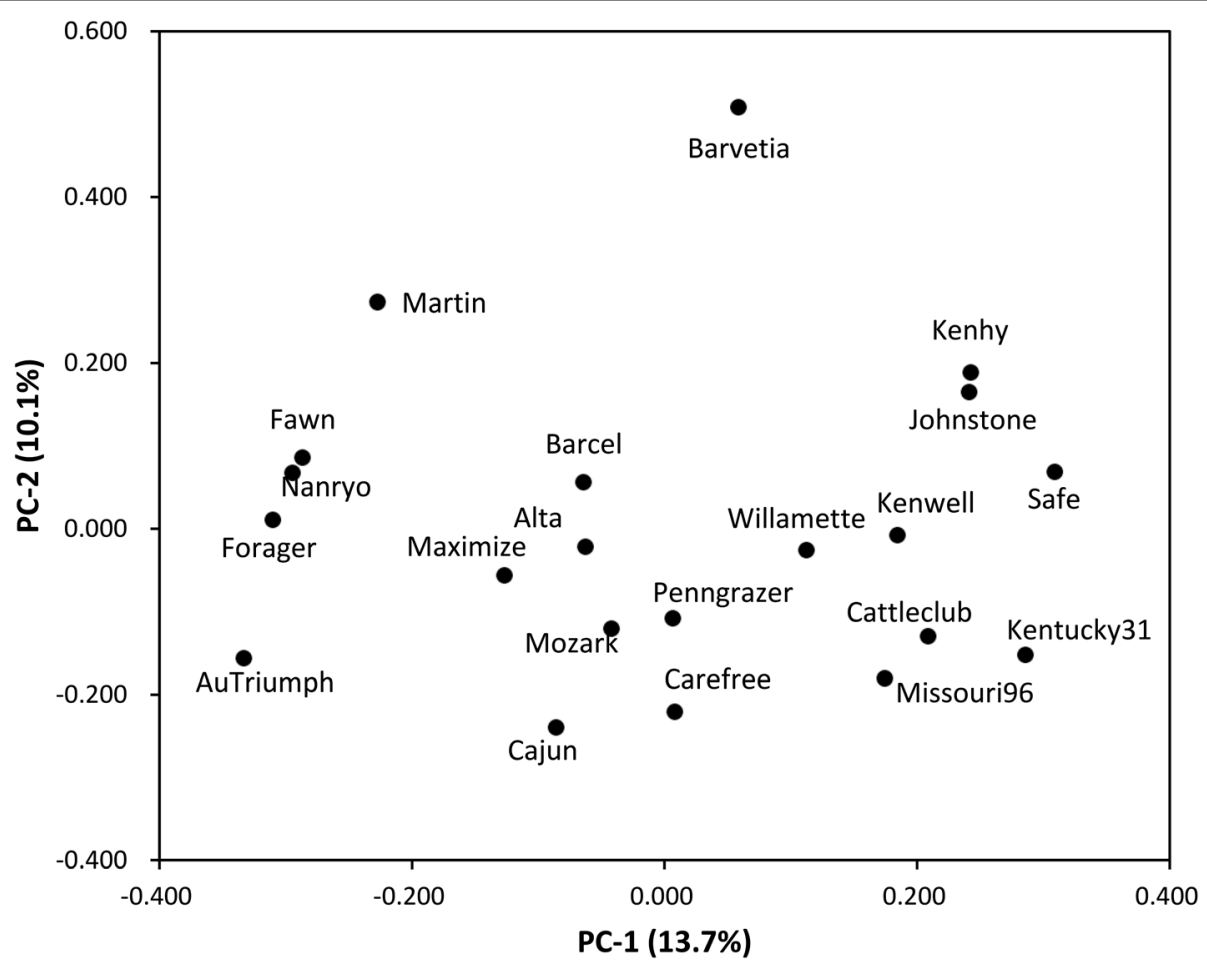

Fig. 2 Principal coordinates analysis (PCOA) scatterplot of 21 tall fescue cultivars based on the first two principal coordinates 
Structure program. We investigated the range from $\mathrm{K}=$ 1 to $K=10$ and calculated the posterior probability for each value of $\mathrm{K}$ using the estimated log likelihood of $\mathrm{K}$. The number of clusters best fitting the data was $K=3$ as indicated by the modal value of $\Delta \mathrm{K}$. As a result, the studied cultivars were successfully assigned to three subgroups with slight mixing $(\mathrm{K}=3, \Delta \mathrm{K}=65.37)$ as represented in Fig. 1 and Table 3; inferred clusters were calculated with more than $60 \%$ probability intervals. In general, the clustering based on Bayesian statistics was found to be in consistency with distance based NJ clustering, whereas there were deviations and fragmentation of genetic clusters because of admixed cultivars such as Alta, Barvetia and Barcel. A second analysis of each cultivar assignment probabilities for the model $\mathrm{K}=3$ shows that cluster 1 (red) is corresponding to the Clade 6 and Barcel in Clade 3 in NJ dendrogram. The cluster 2 (blue) includes Clade 4 and 5, and Carefree in Clade 2 of NJ tree. Finally, cluster 3 (green) consists of Clade 1, remaining entries except Carefree and Willamette in Clade 3. Moreover, the affinities produced by PCoA are generally in agreement with the results of the STRUCTURE analysis, since the PCoA grouped the cultivars into three clusters strongly differentiated, which correspond substantially to three inferred sub-clusters from STRUCTURE analysis (Fig. 1). It's worth noting that cultivars Alta, Barvetia and Barcel showed the admixed membership based on Q-matrix values, nor did they reflected clear membership in any of the groups identified in the PCoA. This might be due to the fact that extensively used poly-intercross among genotypes from registered varieties or exchanged germplasm in breeding programs led to disturbed Hardy-Weinberg equilibrium (HWE) and genetic admixture in the synthetic cultivar populations [7].

In this study, due to using a DNA bulking strategy, it was possible to survey the genetic variation among the 21 tall fescue cultivars regardless of intra-cultivar variability. Assaying bulked samples not only drastically reduces the number of individual samples that need to be processed [52], but also results in a preferential elimination of rare alleles by dilution in larger bulk samples $[10,53]$ and therefore simplifies the marker profile of an individual cultivar or accession. In previous studies, various molecular markers have been used to determine diversity among heterogeneous cultivars populations of outcrossing fodder species based on bulked DNA samples $[7,11,12,54-56]$. Likewise, the 21 tall fescue cultivars used in this study were easily characterized using SSR markers. The large number of molecular markers produced in this study showed that SSR patterns based on bulked DNA samples were found to be a fast, reliable, and highly efficient method to analyze genetic relationships among heterogeneous cultivars of tall fescue.
These results will help breeders choose cultivars more genetically distant to be used in crosses in order to obtain transgressive segregation of some agronomic trait in the hybrid descendant populations.

\section{Conclusions}

In conclusion, SSR patterns based on bulked DNA samples were found to be a good method of choice to evaluate the extent of genetic variability and relationships among 21 heterogeneous tall fescue cultivars. Even though low levels of diversity were detected here, most of SSR markers showed extremely high discriminatory power for evaluated cultivars. SSR analysis is therefore a powerful tool for distinguishing synthetic cultivars as well as assessing genetic relationships among cultivars in outcrossing grass species.

\section{Abbreviations}

AFLP, amplified fragment length polymorphism; AMOVA, analysis of molecular variance; $C T A B$, hexadecyl trimethyl ammonium bromide; $D$, discriminating power; DV, distinguished varieties; GD, genetic distance; GS, genetic similarity; I, Shannon information index; NJ, neighbour-joining; $P$, polymorphic rate; $\mathrm{PB}$, polymorphic bands; $\mathrm{PCoA}$, principal coordinate analysis; PCR, polymerase chain reaction; PIC, polymorphism information content; PIC, the polymorphism information content; PPB, the percentage of polymorphic bands; PPs, primer pairs; RFLP, restriction fragment length polymorphism; SSR, simple sequence repeats; TB, total number of bands

\section{Acknowledgments}

We thank all the participants from the Department of Grassland Science at Sichuan Agricultural University for their contributions to this study. We are also grateful to the U.S. National Plant Germplasm System (NPGS) for providing most of seed materials. This work was funded by National Key Basic Research Program of China (\#2014CB138705), the National Science and Technology Supporting Project (\#2012BAD13B06) and the Earmarked Fund for the Modern Agro-Industry Technology Research System (\#CARS-35-05). The funders had no role in study design, data collection and analysis, decision to publish, or preparation of the manuscript.

\section{Authors' contributions}

$\mathrm{XM}$ and S-QB conceived the project and designed the experiments. K-XF, Z$H G, W-D W$ and MS performed the experiment. K-XF, Z-HG, and XM wrote the paper. X-QZ, YF, D-XL, YP and L-KH gave comments on the manuscript. $\mathrm{XM}$ and S-QB revised the paper. All authors discussed the results and commented on the manuscript. All authors read and approved the final manuscript.

\section{Competing interests}

The authors declare that they have no competing interests.

\section{Author details \\ ${ }^{1}$ Animal Science and Technology College, Sichuan Agricultural University, Chengdu 611130, China. ${ }^{2}$ Chongqing Municipal Institute of Animal Husbandry, Chongqing 400039, China. ${ }^{3}$ Sichuan Academy of Grassland Science, Chengdu 611731, China.}

Received: 1 June 2016 Accepted: 27 July 2016

Published online: 11 August 2016

\section{References}

1. Sleper DA. Breeding tall fescue. Plant Breeding Rev. 1985;3:313-42.

2. Sleper DA, Buckner RC. The fescues. In: Barnes RF, Miller DA, Nelson CJ, Heath ME, editors. Forages, vol. 1. Ames: lowa State University Press; 1995. p. 345-56.

3. Humphreys MW, Thomas HM, Morgan WG, Meredith MR, Harper JA, Thomas H, Zwierzkowski Z, Ghesquiere M. Discriminating the ancestral progenitors of hexaploid Festuca arundinacea using genomic in situ hybridization. Heredity. 1995;75(2):171-4. 
4. Xu WW, Sleper DA, Krause GF. Genetic diversity of tall fescue germplasm based on RFLPs. Crop Sci. 1994;34(1):246-52.

5. Majidi MM, Mirlohi A, Amini F. Genetic variation, heritability and correlations of agro-morphological traits in tall fescue (Festuca arundinacea Schreb.). Euphytica. 2009;167(3):323-31.

6. Golembiewski RC, Danneberger TK, Sweeney PM. Potential of RAPD markers for use in the identification of creeping bentgrass cultivars. Crop Sci. 1997;37(1):212-4

7. Rognli OA, Saha MC, Bhamidimarri S, van der Heijden S. Fescues. In: Boller B, Posselt UK, Veronesi F, editors. Fodder crops and amenity grasses, handbook of plant breeding 5. New York: Springer; 2010. p. 261-92.

8. Busti A, Caceres ME, Calderini O, Arcioni S, Pupilli F. RFLP markers for cultivar identification in tall fescue (Festuca arundinacea Schreb.). Genet Resour Crop Ev. 2004;51(4):443-8

9. Huff DR, Peakall $R$, Smouse PE. RAPD variation within and among natura populations of outcrossing buffalograss [Buchloe dactyloides (Nutt.) Engelm. ]. Theor Appl Genet. 1993;86(8):927-34.

10. Reyes-Valdés MH, Santacruz-Varela A, Martínez O, Simpson J, HayanoKanashiro C, Cortés-Romero C. Analysis and optimization of bulk DNA sampling with binary scoring for germplasm characterization. 2013.

11. Jiang LF, Zhang XQ, Ma X, Huang LK, Xie WG, Ma YM, Zhao YF. Identification of orchardgrass (Dactylis glomerata L.) cultivars by using simple sequence repeat markers. Genet Mol Res. 2013;12(4):5111-23.

12. Forster JW, Jones ES, Kölliker R, Drayton MC, Dupal MP, Guthridge KM, Smith KF, Henry RJ. Application of DNA profiling to an outbreeding forage species, Plant genotyping: the DNA fingerprinting of plants. 2001. p. 299-320.

13. Mian MA, Hopkins AA, Zwonitzer JC. Determination of genetic diversity in tall fescue with AFLP markers. Crop Sci. 2002;42(3):944-50.

14. Gupta PK, Varshney RK, Sharma PC, Ramesh B. Molecular markers and their applications in wheat breeding. Plant Breeding. 1999;118(5):369-90.

15. Saha MC, Mian MR, Eujayl I, Zwonitzer JC, Wang L, May GD. Tall fescue ESTSSR markers with transferability across several grass species. Theor Appl Genet. 2004;109(4):783-91.

16. Saha MC, Cooper JD, Mian MR, Chekhovskiy K, May GD. Tall fescue genomic SSR markers: development and transferability across multiple grass species. Theor Appl Genet. 2006:113(8):1449-58.

17. Hirata M, Cai H, Inoue M, Yuyama N, Miura Y, Komatsu T, Takamizo T, Fujimori M. Development of simple sequence repeat (SSR) markers and construction of an SSR-based linkage map in Italian ryegrass (Lolium multiflorum Lam.). Theor Appl Genet. 2006;113(2):270-9.

18. Elazreg H, Ghariani S, Chtourou-Ghorbel N, Chakroun M, Trifi-Farah N. SSRs transferability and genetic diversity of Tunisian Festuca arundinacea and Lolium perenne. Biochem Syst Ecol. 2011;39(2):79-87.

19. Asay KH, Frakes RV, Buckner RC. Breeding and cultivars, Tall fescue. 1979. p. 111-39.

20. Allen GC, Flores-Vergara MA, Krasynanski S, Kumar S, Thompson WF. A modified protocol for rapid DNA isolation from plant tissues using cetyltrimethylammonium bromide. Nat Protoc. 2006;1(5):2320-5.

21. Shannon CE. A mathematical theory of communication. J Bell Syst Tech. 1948;27:379-423. 623-56.

22. Anderson JA, Churchill GA, Autrique JE, Tanksley SD, Sorrells ME. Optimizing parental selection for genetic linkage maps. Genome. 1993;36(1):181-6.

23. Tessier C, David J, This P, Boursiquot J, Charrier A. Optimization of the choice of molecular markers for varietal identification in Vitis vinifera $\mathrm{L}$. Theor Appl Genet. 1999:98(1):171-7.

24. Rohlf FJ. NTSYS-PC, numerical taxonomy system for the PC, Exeter Software, Version 2.1. 2000. Applied Biostatistics Inc Setauket, USA.

25. Hampl V, Pavlícek A, Flegr J. Construction and bootstrap analysis of DNA fingerprinting-based phylogenetic trees with the freeware program FreeTree: application to trichomonad parasites. Int J Syst Evol Micr. 2001;51(3):731-5.

26. Pritchard JK, Stephens M, Donnelly P. Inference of population structure using multilocus genotype data. Genetics. 2000;155(2):945-59.

27. Evanno G, Regnaut S, Goudet J. Detecting the number of clusters of individuals using the software STRUCTURE: a simulation study. Mol Ecol. 2005;14(8):2611-20.

28. Earl DA. STRUCTURE HARVESTER: a website and program for visualizing STRUCTURE output and implementing the Evanno method. Conserv Genet Resour. 2012;4(2):359-61.

29. Jakobsson M, Rosenberg NA. CLUMPP: a cluster matching and permutation program for dealing with label switching and multimodality in analysis of population structure. Bioinformatics. 2007;23(14):1801-6.
30. Ramasamy RK, Ramasamy S, Bindroo BB, Naik VG. STRUCTURE PLOT: a program for drawing elegant STRUCTURE bar plots in user friendly interface. SpringerPlus. 2014;3(1):431

31. Garg G, Sharma V. Assessment of fatty acid content and genetic diversity in Eruca sativa (L.)(Taramira) using ISSR markers. Biomass Bioenerg. 2015;76:118-29.

32. Kubik C, Sawkins M, Meyer WA, Gaut BS. Genetic diversity in seven perennial ryegrass (L.) cultivars based on SSR markers. Crop Sci. 2001;41(5):1565-72.

33. Hand ML, Cogan NO, Forster JW. Molecular characterisation and interpretation of genetic diversity within globally distributed germplasm collections of tall fescue (Festuca arundinacea Schreb.) and meadow fescue (F. pratensis Huds.). Theor Appl Genet. 2012;124(6):1127-37.

34. Larson SR, Jones TA, Jensen KB. Population structure in Pseudoroegneria spicata (Poaceae: Triticeae) modeled by Bayesian clustering of AFLP genotypes. Am J Bot. 2004;91(11):1789-801.

35. Tehrani MS, Mardi M, Sahebi J, Catalán P. Díaz-Pérez A. Genetic diversity and structure among Iranian tall fescue populations based on genomic-SSR and EST-SSR marker analysis. Plant Syst Evol. 2009;282(1-2):57-70.

36. Buckner RE, Boling JA, Burrus PB, Bush LP, Hemken RA. Registration of Johnstone tall fescue (Reg. No. 23). Crop Sci. 1983;23(2):399-400.

37. Abernethy RH, Steiner JJ, Wofford DS, Thiel DS. Classification and pedigree verification of tall fescue cultivars utilizing the prolamin seed protein fraction. Crop Sci. 1989:29(3):791-7.

38. Buckner RC, Burrus PB, Bush LP. Registration of Kenhy tall fescue (Reg. No. 12). Crop Sci. 1977:17(4):672-3.

39. Buckner RC, Burrus PB. Registration of Kenwell tall fescue (Reg. No. 5). Crop Sci. 1968:8(3):398.

40. Fergus EN, Buckner RC. Registration of Kentucky 31 tall fescue (Reg. No. 7). Crop Sci. 1972;12(5):714.

41. Hoveland CS. Origin and history of tall fescue. In: Fribourg HA, Hannaway DB, West CP, editors. Tall fescue for the twenty-first century. Madison, WI: American Society of Agronomy, Crop Science Society of America, Soil Science Society of America; 2009. p 3-10.

42. Asay KH, Sleper DA. Registration of Missouri-96 tall fescue (Reg. No. 15). Crop Sci. 1979;19(4):563.

43. Hollowell EA. Registration of varieties and strains of grasses, I. Agron J. 1945; 37(8):653-4

44. Rose-Fricker CA, Meyer WA, Van Wuk JP. Registration of Maximize tall fescue. Crop Sci. 1993;33:203.

45. Pedersen JF, Haaland RL, Hoveland CS, Berry CD, Schmidt SP, Harris RR. Registration of Au Triumph tall fescue (Reg. No. 21). Crop Sci. 1983;23(1):182.

46. Pedersen JF, McVeigh KJ, Edminster CW. Registration of Cajun tall fescue. Crop Sci. 1989:29(1):236-7.

47. van Santen E. Animal preference of tall fescue during reproductive growth in the spring. Agron J. 1992;84(6):979-82.

48. Kubik C, Honig JA, Meyer WA, Bonos SA. Genetic diversity of creeping bentgrass cultivars using SSR markers. Int Turfgrass Soc Res J. 2009;11:533-47.

49. Baluch SJ, Stratton SD, Buker RJ. Registration of Forager tall fescue (Reg. No. 17). Crop Sci. 1980:20(5):670.

50. Kindiger B, Gau M, Hasegawa H, Katsura M, Ueyama Y, Goto K, Sato S, Yoshiyama T, Terada Y, Tsurumi Y. Registration of Nanryo tall fescue. Crop Sci. 2006;46(4):1815-6.

51. Sleper DA, Mayland HF, Crawford RJ, Shewmaker GE, Massie MD. Registration of HiMag tall fescue germplasm. Crop Sci. 2002;42:318-9.

52. Fu Y, Legge WG, Clarke JM, Richards KW. Genetic variation and relationships of pedigree-known oat, wheat, and barley cultivars releaved by bulking and single-plant sampling. Genet Resour Crop Ev. 2006;53(6):1153-64.

53. Michelmore RW, Paran I, Kesseli RV. Identification of markers linked to disease-resistance genes by bulked segregant analysis: a rapid method to detect markers in specific genomic regions by using segregating populations. Proc Natl Acad Sci U S A. 1991;88(21):9828-32.

54. Yu K, Pauls KP. Rapid estimation of genetic relatedness among heterogeneous populations of alfalfa by random amplification of bulked genomic DNA samples. Theor Appl Genet. 1993;86(6):788-94.

55. Sweeney PM, Danneberger TK. RAPD markers from perennial ryegrass DNA extracted from seeds. Hortscience. 1997:32(7):1212-5.

56. Huang $T$, Ma X, Zhang XQ, Zhang XY, Zhang RZ FUKX. Comparation of SSR Molecular Markers Analysis of Annual Ryegrass Varieties in DUS Testing. Sci Agr Sin. 2015;48(2):381-9. 